\title{
AC 2008-2300: USING LET ME LEARN® TO PROMOTE METACOGNITION AND FOSTER TEAMING SKILLS
}

\section{Kevin Dahm, Rowan University}

Kevin Dahm is an Associate Professor of Chemical Engineering at Rowan University and a certified Let Me Learn ${ }^{\circledR}$ consultant. He earned his BS at Worcester Polytechnic Institute (92) and his PhD at Massachusetts Institute of Technology (98). He is the recipient of several ASEE awards, including the 2002 PIC-III Best Paper Award, the 2003 Joseph J. Martin Award and the 2004 Raymond W. Fahien Award.

\section{Roberta Harvey, Rowan University}

Roberta Harvey is an Associate Professor in the Department of Writing Arts at Rowan University and a certified Let Me Learn ${ }^{\circledR}$ Consultant. She teaches writing to engineering and biology students and serves as Coordinator of the First-Year Writing Program. She has been teaching with the Rowan Sophomore Engineering Clinic team since 1998. She received her Ph.D. in English with a specialization in Composition and Rhetoric from the University of Wisconsin-Milwaukee. 


\title{
Using Let Me Learn® to Promote Metacognition and Foster Teaming Skills
}

\begin{abstract}
The Sophomore Engineering Clinic at Rowan University is a course in technical writing and engineering design, team-taught by Communications and Engineering faculty. This fall sophomore course presents Rowan engineering students with their first exposure to open-ended design problems in a team setting. The current course features a four-week introductory project on bottle rocket design, completed in teams of 3-4, and a 10-week main project on crane design, completed in teams of 4-5. The teaming aspect of the course is a challenge to engineering students, particularly in that many of them are naturally pre-disposed to prefer working alone.
\end{abstract}

The Let Me Learn (LML) Process is an integrated approach to teaching and learning that starts with administration of the Learning Connections Inventory (LCI), a survey instrument that assesses individual learning patterns. All Rowan Students now take the LCI as entering freshmen. In this study, short in-class team problem solving exercises are being conducted in two of the six sections of the Fall 2007 offering of the course. The LML process is then being used to help students interpret their team's behaviors and prepare strategies for effective teaming on the course's long-term projects. This intervention started immediately after the 4-week bottle rocket project was completed.

This paper will describe the team-building activities and use several mechanisms to assess their effectiveness. The teams in the two LML sections will be compared to the other four sections through two instruments: performance on team deliverables and peer evaluations. In addition, the peer evaluations on the bottle rocket and crane projects will be compared to each other, to gauge how students' effectiveness at working in teams was influenced by the team-building activities.

\section{Introduction}

A large body of research in engineering education has been devoted to the study of engineering student teams. Numerous published studies examine understanding the factors that shape the dynamics, interactions, and performance of teams, identifying pedagogical strategies and resources that improve team functioning, and developing methods of assessment to measure team skills ${ }^{1,2,3,4,5,6}$. Among the factors that have been studied are students' learning processes, commonly measured using learning styles inventories such as the Meyers-Briggs ${ }^{7}$ and Felder ${ }^{89}$ inventories.

This study employs a particular instrument, the Learning Connections Inventory, and methodology, the Let Me Learn ${ }^{\circledR}$ process, for characterizing the individual learning processes of students. The Let Me Learn ${ }^{\circledR}$ (LML) process is a comprehensive strategy for building metacognitive awareness in students. LML differs from learning styles approaches in that learning styles typically identify the learner with a personality type or category rather than a profile reflecting degree of preference for multiple interacting patterns. Another key difference is that LML emphasizes the learner's capacity to use his/her patterns consciously and strategically to adapt to different learning expectations, rather than merely seeking learning 
conditions compatible with his/her learning style. The process begins by having students take the Learning Connections Inventory (LCI). Responses to the LCI's 28 statements about learning preferences, using a 5-point scale ranging from Always to Never Ever, yield a profile of the extent to which an individual utilizes each of four types of patterned learning processes, listed below with some of the key preferences characterizing each pattern:

- Sequence (organization, planning, order, structure)

- Precision (information, details, knowing for the sake of knowing)

- Technical Reasoning (hands-on learning, relevance, self-sufficiency)

- Confluence (risk, innovation, alternative views, freedom from rules)

All learners are capable of using any or all of these patterns but have preferences which the LCI quantifies. The scaled responses are scored on a scale of 1 (Never Ever) to 5 (Always) and there are seven statements associated with each of the four learning patterns, so scores for each pattern range from 7 to 35 . Each individual pattern is measured along a continuum of "Use First" (2535), "Use as Needed" (18-24), or "Avoid" (7-17). Once a student understands his/her own learning patterns, he or she can:

- Forge or intensify use of patterns that he or she prefers to avoid or use only as needed, but needs for particular tasks

- Tether, or reduce, use of preferred, but task-inappropriate, patterns

- Understand, appreciate and value peers who have different learning patterns

- Formulate effective strategies for group tasks based on individual learning patterns of team members

LML has now been implemented with thousands of K-12 students. It has been shown ${ }^{10}$ that children as young as six years old can learn to do these things. LML has been demonstrated to not only improve student learning, but also attitude towards school and working relationship with peers and teachers. LML is also used at more than a dozen higher education institutions and in several corporate settings nationally and internationally. ${ }^{10}$ The authors, however, are aware of no cases outside Rowan University where LML has been applied specifically to engineering education.

This study investigates the use of LML in engineering education in the context of the Sophomore Engineering Clinic, a course at Rowan University that covers technical writing and engineering design and is team-taught by communication and engineering faculty. The course consists of two 75-minute lecture periods devoted to technical writing instruction and one three-hour lab period per week. Most of the graded assignments in the course are written reports about the design projects completed in lab. The design and communication components of Sophomore Clinic have been reported elsewhere ${ }^{11,12}$, as has the application of LML to understanding the challenges faced by many engineering students in writing courses. ${ }^{13}$

In 2006 the Sophomore Engineering Clinic was divided into six sections of approximately 20 students. All six sections participated in a common three-hour weekly lab, and completed the same design projects and writing assignments. The Let Me Learn ${ }^{\circledR}$ process was implemented in two of the six sections by the writing instructor; the other four sections did not use LML. At the 
end of the semester, students were given a survey that asked them to rate their agreement with the following four statements on a scale where $1=$ strongly agree and $4=$ strongly disagree:

\section{My team worked together to DEFINE its project goal(s).}

\section{My team worked together to REACH its project goal(s).}

\section{My team RECOGNIZED my skills, knowledge, and abilities.}

\section{My team effectively UTILIZED my skills, knowledge, and abilities.}

In general, students in one of the two sections that received intensive LML instruction had more positive responses than the other sections, and the mean scores of these two sections were more positive than the combined average of all sections. Most importantly, among students with the pattern combination of Use-First Technical Reasoning and Use-First Confluence, the combination that most frequently resulted in low team performance ratings from peers, mean score were much higher for those who were in LML sections than for those who were not. These findings suggested that in terms of student perception of alignment with their team's goals and team appreciation of their contributions, LML awareness promoted better team relations. This self-assessment was the only hard data collected. ${ }^{14}$

In 2007, the Sophomore Clinic was once again divided into six sections, with LML implemented in two of the six. This paper will describe the specific approaches used for integrating LML into Sophomore Clinic. It will also describe a comparative assessment of the LML and control sections using two metrics: performance on team deliverables and peer evaluations.

\section{Background and Methodology}

An earlier study of chemical engineering students working in teams in the Junior/Senior Clinic at Rowan University found that students' perception of team experiences as well as their performance on team projects were positively influenced by instruction in learning pattern differences coupled with ongoing reflection in the form of periodic writing assignments. Teams who received this instruction exhibited improved perceptions of teamwork and scored higher on a team project assessment than teams who did not. ${ }^{15}$ The current study was undertaken for several reasons. Because we had over 20 teams all working on the same project, the Sophomore Clinic course provided us with a much larger and more uniform sample. We also had the opportunity to compare various levels of intervention and examine what level of intervention is necessary to gain a persistent understanding and application of the LML process.

The faculty assign the teams for the major design projects in the course. In all six sections of the course, information about student course and work schedules, study habits, major, and GPA were taken into consideration in order to create compatible teams. The LCI scores for all students were available as Rowan University now administers this instrument to all incoming students in all majors. Of the six sections of Sophomore Clinic, two received no instruction and engaged in no activities involving the LCI beyond taking the LCI as Freshmen, and LCI scores were not considered when we formed the teams. For two of the remaining sections, LCI scores were used in addition to the other factors in order to balance the composition of the teams according to 
learning patterns. Students were reminded of what their LCI scores were and occasional references to the characteristics of the four patterns were made in discussing course assignments and expectations.

Teams in the final two sections were formed with all of the above factors taken into consideration. These students also engaged in the following learning activities relating to teamwork and/or learning pattern awareness:

- Participating in a learning pattern awareness activity

- Writing a team agreement

- Developing individual pattern-specific strategies for writing a team paper

- Reassessing each team member's contributions in light of the team's expectations and needs

Each of these activities is described in detail below.

Learning pattern awareness activity: Before the teams for the final design project were assigned, students were assigned to groups for a one-day activity intended to raise awareness of how learning patterns are manifested when approaching a challenging task that must be undertaken as a group. Students were assigned in order to create groups with a wide diversity of learning patterns; ideally, the group would include at least one person representing each pattern at a "use first" level.

In this case, the activity used was the construction of towers out of Jenga blocks. Each team received a box of 54 blocks (approximate dimensions 3"x 1"x 9/16") and a typewritten set of instructions. First, student teams were simply tasked with building the tallest tower possible, using only Jenga blocks, within a 10 minute time frame. After completing this activity, students were given specifications for computing the "cost" and "revenue" associated with building a tower (e.g., revenues for achieving different height thresholds and costs associated with using varied numbers of blocks) and instructed to build a tower that maximized profit. This time students had 25 minutes, but were not permitted to ask questions of the instructors during the time.

Of course, the real purpose of the activity is not to build towers, but to see how different learners bring different approaches to the problem. The activity also illustrates the importance of applying appropriate learning strategies to meet task expectations and simply dramatizes the reality of the learning patterns measured by the LCI. Following the activity, we led a follow-up discussion with the students in which we discussed their observations and their reactions. Among the observations from this discussion:

$>$ Most of the students were use-first technical learners. This pattern served them well in the first activity, when building the tallest tower was the sole goal. However, a purely technical approach was unsatisfactory for the second problem. Some teams failed to read the instructions carefully and completed the task without actually understanding the goal. In one extreme case a team built a tower without ever attempting to compute its profit. (It turned out to be negative.) 
Sequential and precise learners tended to be frustrated by perceived ambiguities in the instructions and the restriction against asking questions in the second activity. However, teams on which sequential and/or precise learners took a leadership role were more likely to stay "on task," attempting to optimize profit rather than height.

At the lab period following this one-day activity (in one case the next day, in one case the same day) students received their team assignments for the 10-week design project. Their first assignment was writing the Team Agreement, described in the next section.

Team agreement: Each team met and composed a written agreement stating their expectations for conduct and identifying the responsibilities, skills, and strengths of each team member. One required element of the team agreement was a plot of the team's LCI profiles. The skills and strengths inventory included learning pattern characteristics, and teams were encouraged to assign responsibilities based on what a given team member was likely to be good at. Students high in sequence and precision were generally asked to assume primary responsibility for the team's project notebook, while students high in technical were likely to be asked to take the lead on producing drawings and fabricating project components. The team agreement has two main purposes. First, it articulates the team's expectations of each other, which usually include items such as coming to meetings, performing assigned tasks, communicating with the team, contributing ideas, and supporting other team members. These expectations are not unusual and most teams would agree they are important. However, depending on their specific learning patterns, individual students might assign different — and potentially conflicting - levels of priority to these expectations if they are not made explicit. The team agreement puts them "on the table" and requires all team members to commit to them. Second, the team agreement recognizes the value of each team member. Again, it is not unusual to expect that a team would want to make the best use of its talent and would conduct some kind of inventory. In this case, however, the team agreement foregrounds the kind of learning that each individual would bring to the project. Instead of being driven by what the team identifies as its wants or needs, contributions are defined by the opportunities presented by the individual's learning patterns. Thus, in addition to assigning notebook responsibilities to a team member high in sequence and precision, the team also had to consider what role would best be assigned to a team member high in confluence, the pattern associated with innovation and risk-taking. The team agreement is thus intended to set the tone for a team dynamic based on the idea that all four learning patterns are needed for success.

An essential aspect of the Let Me Learn ${ }^{\circledR}$ process is that it calls for individual learners to take responsibility for understanding task expectations and applying their learning patterns intentionally rather than merely intuitively. That is, even though the team agreement encouraged the team to value its members based on who they are as learners, no one could effectively meet the team's expectations simply by being who they are. The learning activities that followed the team agreement were designed to take this next step.

Individual pattern-specific strategies for writing a team paper: The first writing assignment relating to the major project is a progress report that the team writes collaboratively. In connection with a prior individual writing assignment, a white paper on an engineering solution, students were asked to write self-descriptions of their learning patterns, to analyze the pattern- 
specific demands of the assignment, and to identify strategies they would need to use to successfully complete the assignment. In preparation for writing the progress report, students were asked to continue this kind of strategizing with respect to the expectations of the team. Figure 1 shows the form used to guide students in the process of formulating strategies.

Reassessment of each team member's contributions: During the final weeks of the semester, as the project drew to a close, the teams were asked to review the responsibilities that had been assigned to each team member, reflect on why the team valued the contributions of that team member, and decide, in essence, whether that team member was meeting the needs and expectations of the team and determine whether he/she should continue to perform at the same level, increase the quality of his/her contributions, or assume new or additional responsibilities. At this point, we expected that students would be able to use the "vocabulary" of learning patterns as a way of evaluating how well each team member was meeting the team's expectations without becoming judgmental and to help each team member use his/her learning patterns to contribute to the team's success. Figure 2 shows the questionnaire used.

\section{Assessments}

Two measures were used to assess whether the LML activities described in the previous section had an impact on the dynamics and performance of student teams: performance on team deliverables and peer evaluations.

\section{Peer Evaluation}

The 2007 course had two major team projects: a four week project on bottle rocket design followed by a 10-week project on crane design. Both projects have been described in detail

previously. ${ }^{16,17}$ At the end of each project, students were asked to complete an evaluation themselves and their teammates using the peer evaluation form widely disseminated by Felder ${ }^{18}$ and shown in Figure 3. This form asks students to rate their own effort and that of each of their teammates on a scale from "excellent" to "no show" and then provide specific evidence to support their ratings.

One intent of the LML activities described above is to empower students to understand and appreciate people whose learning patterns differ from their own. Consequently it was hypothesized that use of LML would lead to more effective collaborations between students, as measured by peer evaluations. In the two LML sections, the activities described in the "Background and Methodology" section were initiated after the 4-week bottle rocket project was completed. The learning pattern awareness activity was conducted the day before teams for the 10 -week project were assigned. Consequently, the course instruction and project specifications were essentially identical for all six sections for the bottle rocket project. The intent behind this organization was for the bottle rocket peer evaluations to serve as an additional control, detecting differences between the sections that might be attributable to factors besides use of LML.

The results are summarized in Table 1. As it turned out, there was essentially no difference between the LML and control cohorts on either project, at least as measured by the peer evaluations. 
Table 1: Summary of peer evaluations for bottle rocket and crane design projects.

\begin{tabular}{|l|c|c|}
\hline & LML Sections & Control Sections \\
\hline Number of students & $\mathbf{3 1}$ & $\mathbf{7 6}$ \\
\hline Mean Student SELF evaluation, Bottle Rocket & $\mathbf{7 . 1 3}$ & $\mathbf{6 . 9 9}$ \\
\hline Mean Student TEAMMATE evaluation, Bottle Rocket & $\mathbf{6 . 9 4}$ & $\mathbf{6 . 9 0}$ \\
\hline Mean Student SELF evaluation, Crane & $\mathbf{7 . 3 1}$ & $\mathbf{7 . 2 4}$ \\
\hline Mean Student TEAMMATE evaluation, Crane & $\mathbf{6 . 8 4}$ & $\mathbf{6 . 8 5}$ \\
\hline \% of ratings "marginal" or worse, Bottle Rocket & $\mathbf{4 . 5 \%}$ & $\mathbf{3 . 8 \%}$ \\
\hline \% of ratings "marginal" or worse, Crane & $\mathbf{7 . 0 \%}$ & $\mathbf{7 . 3 \%}$ \\
\hline
\end{tabular}

Note: Peer evaluation scores from the Felder form were converted to numerical ratings as follows:

$8=$ =xcellent, $7=$ =ery good, $6=$ satisfactory, $5=$ =rdinary, $4=$ =marginal, $3=$ =deficient, $2=$ =unsatisfactory, $1=$ superficial, $\mathbf{0}=$ no show.

\section{Performance on Team Deliverables}

The two major team deliverables on the Crane design project were the final report and the technical merit of the crane itself. Each report was graded by one writing instructor and two engineering instructors using detailed grading rubrics, an example of which is shown in Figure 4. The rubrics were circulated to the students well before the due date, and so served both to communicate clear expectations for the assignment and also to ensure that expectations and grading would be uniform across all six sections. The technical merit of each crane design was evaluated by the "performance equation":

Performance $=\mathrm{W} / \mathrm{C}$

Where $\mathrm{C}=\mathrm{Cost}$ of aluminum and plastic bar stock used to construct the truss, and $\mathrm{W}=\mathrm{Weight}$ successfully lifted. (Twenty $70 \mathrm{lb}$ weights were available and teams were permitted to attempt three lifts, the first with the minimum $70 \mathrm{lbs}$ and the second and third with loads of their choice.)

Performance scores ranged from a maximum of $257 \mathrm{lbs} / \$$ to a minimum of 0 . Benchmarks were then established (highest performance score $=100 \%$, performance of $100 \mathrm{lbs} / \$=80 \%$, etc.) and linear scales between the benchmarks were used to convert raw performance scores into technical merit grades.

Table 2: Summary of grades on team deliverables.

\begin{tabular}{|l|c|c|}
\hline & Let Me Learn & Control \\
\hline Mean Final Report Grade & 78.5 & 84.0 \\
\hline Mean Technical Merit Grade & 73.0 & 84.0 \\
\hline Number of Teams & 7 & 18 \\
\hline
\end{tabular}

Table 2 summarizes the grades earned by teams in the LML and control sections for technical performance and for the final report. On average, the teams in the control sections scored higher, though the differences were not statistically significant to $95 \%$ confidence. Note that in five years running the crane project with over 120 teams; only one team has ever failed to lift the minimum weight. The results shown in Table 2 are somewhat skewed by the presence of that team in one of this year's LML sections (which only had 7 teams total). However, there is 
clearly no evidence that the LML activities undertaken in this study led to improved performance on team deliverables.

\section{Summary and Conclusions}

The Let Me Learn ${ }^{\circledR}$ process is a comprehensive learning strategy intended to foster metacognitive behaviors in learners. It starts by using the LCI survey as an instrument for quantifying a student's preference for various learning patterns. Students can then use this knowledge to formulate strategies for approaching tasks and identify barriers to learning.

The Sophomore Engineering Clinic is a course taken by all engineering disciplines that features a 10 -week team design project. The intent behind integrating LML into Sophomore Engineering Clinic was that if students were aware of their own learning preferences and patterns as well as those of their teammates, they would be better able to formulate effective strategies and make use of complementary skill sets, and also better able to avoid or resolve conflict. In a previous study use of LML in Sophomore Clinic was shown to produce teams that worked together more effectively than teams not using LML, and that in LML teams all members were more likely to feel they contributed meaningfully to the project. However these findings were based solely on self-assessment.

In the present study, LML was integrated into two sections of Sophomore Clinic and team performance was assessed using peer evaluations and performance on team deliverables. There was no evidence that the LML process led to improved team performance by these metrics. This outcome contrasted a previous study in which a comparable use of LML led to improved performance on team deliverables in the Rowan Junior/Senior Engineering Clinic.

The primary conclusion we draw from these various findings is that more work needs to be done to evaluate the impact and pedagogical benefit, if any, of LML for teaming skills and team performance. At the start of the Sophomore Clinic students have essentially identical backgrounds, as the Freshman curriculum for all engineering disciplines is nearly identical. Consequently, while Sophomore Clinic projects are completed in teams of 4-5, the design projects are such that any one student has all the skills needed to complete every aspect of the project. Thus, it is possible for teams to display behaviors that represent poor teaming (e.g., one or two students do essentially all the work, one team members' ideas are routinely ignored, etc.) and still produce excellent team deliverables. This observation may explain the apparent contradiction between the 2006 and 2007 results: that LML leads to more effective teamwork, but not to better team performance.

By contrast in the junior and senior year (and in the workplace) multidisciplinary teams are composed of students with very different skill sets. In a setting where there is interdependency among team members, it is assumed a more direct correlation between teaming skills and objective team performance should exist. Future studies will examine whether emphasizing teaming skills (with or without LML) early in the curriculum has a long-term impact on teaming skills and team performance in the Junior/Senior Engineering Clinic. 


\section{Strategies for Progress Report 1}

This assignment represents the first of three grades that will be subject to the teamwork weighting factor. Using intentional strategies to effectively meet the demands of this assignment is therefore doubly important:

- Your grade on the team's progress report may be reduced if you are not meeting expectations

- The quality of the team's progress report depends on everyone's contributions.

Think about what you know about yourself and about the demands of the progress report, and briefly answer the two questions below.

1. What is the most important strategy for you to use in order to fulfill your personal responsibilities? (In other words, how will you meet your team's expectations?)

2. What is the most important strategy for you to use in order to effectively contribute to the team's success? (In other words, what can you offer that will be most helpful to your team?)

Save this sheet. I will ask you to turn it in to me when you turn in the progress report.

Figure 1. Developing individual pattern-specific strategies for writing a team paper. 


\section{Team Member Progress Assessment Team Number:}

\begin{tabular}{|l|l|l|l|}
\hline $\begin{array}{c}\text { Team } \\
\text { Member }\end{array}$ & $\begin{array}{c}\text { Key Responsibilities, } \\
\text { Skills, Talents, and/or } \\
\text { Learning Patterns }\end{array}$ & $\begin{array}{l}\text { The team values this team } \\
\text { member's contributions } \\
\text { because: }\end{array}$ & $\begin{array}{l}\text { The team needs this team member to } \\
\text { maintain level of contribution and } \\
\text { quality, meet new expectations, and/or } \\
\text { assume additional responsibilities as } \\
\text { specified: }\end{array}$ \\
\hline & & & \\
\hline & & & \\
\hline & & & \\
\hline & & & \\
\hline
\end{tabular}

Figure 2. Reassessment of each team member's contributions. 


\section{Name}

Please write the names of all of your team members, INCLUDING YOURSELF, and rate the degree to which each member fulfilled his/her responsibilities in completing their team assignments. Submit these signed forms to your faculty project manager.

The possible ratings are as follows:

\begin{tabular}{|l|l|}
\hline Excellent & $\begin{array}{l}\text { Consistently went above and beyond-tutored teammates, carried more than his/her fair share } \\
\text { of the load }\end{array}$ \\
\hline Very good & Consistently did what he/she was supposed to do, very well prepared and cooperative \\
\hline Satisfactory & Usually did what he/she was supposed to do, acceptably prepared and cooperative \\
\hline Ordinary & Often did what he/she was supposed to do, minimally prepared and cooperative \\
\hline Marginal & Sometimes failed to show up or complete assignments, rarely prepared \\
\hline Deficient & Often failed to show up or complete assignments, rarely prepared \\
\hline Unsatisfactory & Consistently failed to show up or complete assignments, unprepared \\
\hline Superficial & Practically no participation \\
\hline No show & No participation at all \\
\hline
\end{tabular}

These ratings should reflect each individual's level of participation and effort and sense of responsibility, not his or her academic ability.

\begin{tabular}{|l|l|}
\hline Name of Team Member & Rating \\
\hline & \\
\hline & \\
\hline & \\
\hline & \\
\hline & \\
\hline
\end{tabular}

Your signature:

CR.M. Felder, 1997. Based on the paper presented by Deborah B. Kaufman, Richard M. Felder, Hugh Fuller, "Peer Ratings in Cooperative Learning Teams," Session 1430, 1999 ASEE Annual Conference.

Explanations of the above ratings, and any other comments you wish to make.

Figure 3: Peer evaluation form used for bottle rocket and crane design projects. 
Sophomore Clinic I

Grading Criteria for Assignment 5: Final Design Report on Crane Project

Demonstrates awareness of audience and purpose

Provides key information regarding the project goal, the design approach, and the design solution in the executive summary

Employs appropriate technical style and tone for designated audience; uses first-person sparingly and only where necessary for clarity

Includes appropriate level of detail in the body of the report for designated audience and genre; does not assume that reader already understands what is being discussed

- Summarizes and evaluates performance results in the conclusion

$\square \quad$ Includes essential figures and tables of results in the body of the report; includes requested information in appendices and refers to it in the report

Demonstrates ability to present technical information

Provides complete and logically organized technical description of crane, using specific dimensions, precise language, and correct terminology

Uses figures and/or tables effectively to highlight features of the design, including SolidWorks sideview, table of member forces, and table of materials and costs

Uses figures and tables effectively to show data that informed design optimization

Demonstrates understanding of design practices and ability to apply specific design methods

Summarizes project goal and identifies parameters and constraints

Explains basis for choice of truss family and shows at least 2 ideas that were eliminated

Explains procedures for optimizing final design

$\square$ Describes role of MATLAB in optimization, including how the program was used to determine the optimal truss within the chosen truss family and what steps were taken to verify that MATLAB results were valid

Explains how data were interpreted to make design decisions

Provides a quantitative prediction of the performance of the truss and rationale for the prediction and identifies assumptions made for purposes of analysis

Provides a quantitative comparison of lift results to predictions based on analysis; offers insightful failure analysis if applicable

Demonstrates ability to follow document specifications and meet requirements

- Organizes content according to specified subsections and follows appropriate conventions for each (content, tense, grammatical structure)

Follows document format instructions (including letter format, fonts, margins, labeling of figures and tables, and other specifications given in the Style Sheet)

P Proofreads and corrects errors (spelling, grammar, punctuation)

Demonstrates effective communication and teamwork

Shows evidence of collaboration, exchange, and contributions from all team members (wiki and individual contributions section of report)

Documents design project work, including ideas, data, and other requested content (wiki)

Total

Figure 4. Rubric for final report on design project. 


\section{Bibliography}

${ }^{1}$ P. Lewis, D. Aldridge, P.M. Swamidass, “Assessing teaming skills acquistion on undergraduate project teams," Journal of Engineering Education, April 1998, 149-155.

${ }^{2}$ E. Seat, S.M. Lord, "Enabling effective engineering teams: a program for teaching interaction skills," Journal of Engineering Education, October 1999, 385-390.

${ }^{3}$ C.G. Downing, "Essential non-technical skills for teaming," Journal of Engineering Education, January 2001, 113117.

${ }^{4}$ M.E. Natishan, L.C. Schmidt, P. Mead, "Student focus group results on student team performance issues," Journal of Engineering Education, July 2000, 269-272.

${ }^{5}$ M. Laeser, B.M. Moskal, R. Knecht, D. Lasich, "Engineering design: examining the impact of gender and the team's gender composition," Journal of Engineering Education, January 2003, 49-56.

${ }^{6}$ D. Hunkeler and J.E. Sharp, "Assigning functional groups: the influence of group size, academic record, practical experience, and learning style," Journal of Engineering Education, October 1997, 321-332.

${ }^{7}$ Pittenger, D. J., "The Utility of the Myers-Briggs Type Indicator," Review of Educational Research, 63 (1993).

${ }^{8}$ Felder, R. M., "Reaching the Second Tier: Learning and Teaching Styles in College Science Education," Journal of College Science Teaching, 23, 5 (1993).

${ }^{9}$ Felder, R. M. and Brendt, R. “Understanding Student Differences," Journal of Engineering Education, 94, 1 (2005).

${ }^{10}$ Let Me Learn®, http://www.letmelearn.org/.

${ }^{11}$ D. Acciani, J. Courtney, C. Diao, R. Harvey, B. Pietrucha, W. Riddell, and P. Von Lockette, "Convergingdiverging approach to design in the Sophomore Engineering Clinic," Proceedings of the Annual Conference of the American Society for Engineering Education, 2006.

12 E. Constans, K. Dahm, J. Everett, C. Gabler, R. Harvey, L. Head, H. Zhang, J. Courtney, and D. Hutto, "Setting the multidisciplinary scene: engineering design and communication in the "Hoistinator" project," Proceedings of the Annual Conference of the American Society for Engineering Education, 2005.

${ }^{13}$ R. Harvey, "Beyond learning styles: understanding the learning processes of engineering students through the Interactive Learning Model ${ }^{\mathrm{TM}}$," Proceedings of the Annual Conference of the American Society for Engineering Education, 2004.

${ }^{14}$ K. D. Dahm, R. Harvey, “Using Awareness of Learning Processes to Help Students Develop Effective Learning Strategies," ASEE Annual Conference and Exposition, June 2007, Honolulu, HI.

${ }^{15}$ J. Newell, K. Dahm, R. Harvey, and H. Newell, "Developing metacognitive engineering teams," Chemical Engineering Education, Fall 2004, 316-320.

${ }^{16}$ Von Lockette, P., Riddell, W., Dahm, K., Harvey, R., Courtney, J., Pietrucha, B., Diao, C., Accini, D., "Bottle Rockets and Parametric Design in a Converging-Diverging Design Strategy," ASEE Annual Conference and Exposition, June 2006, Chicago, IL.

${ }^{17}$ E. Constans, J. Courtney, K. Dahm, J. Everett, C. Gabler, R. Harvey, L. Head, D. Hutto, H. Zhang, "Setting the Multidisciplinary Scene: Engineering Design and Communication in the 'Hoistinator' Project", ASEE Annual Conference and Exposition, June 2005, Portland, OR. 
18 Deborah B. Kaufman, Richard M. Felder, Hugh Fuller, "Peer Ratings in Cooperative Learning Teams," Session 1430, 1999 ASEE Annual Conference. 